\title{
A bio-economic model for the ecosystem-based management of the coastal fishery in French Guiana
}

\author{
A.A. CISSÉ \\ IFREMER, Domaine de Suzini, BP 477, 97331 Cayenne, French Guiana, \\ France and CEREGMIA, French Guiana, France. Tel: +594-594-302-200. \\ Email:abdoul.cisse@ifremer.fr
}

\section{S. GOURGUET}

IFREMER, UMR AMURE, Département d.Economie Maritime, France and CNRS, CERSP, MNHN, France.Email: sophie.gourguet@gmail.com

\section{DOYEN}

CNRS, CERSP, MNHN, France.Email: luc.doyen@orange.fr

\author{
F. BLANCHARD \\ IFREMER, French Guiana, France. Email: fabian.blanchard@ifremer.fr
}

\author{
J.-C. PÉREAU \\ GRETHA (UMR CNRS 5113) and University of Bordeaux, France. \\ Email: jean-christophe.pereau@u-bordeaux4.fr
}

\begin{abstract}
This paper offers a theoretical and empirical model of ecosystem-based fishery management. A multi-species and multi-fleet model integrating Lotka-Volterra trophic dynamics as well as production and profit assessments is developed and applied to the coastal fishery of French Guiana. This small-scale fishery constitutes a challenging example with high fish biodiversity, several non-selective fleets and a potentially increasing local food demand due to demographic growth. The dynamic model is calibrated with 13 species and four fleets using monthly catch and effort data from 2006 to 2009 . Several contrasted fishing scenarios including status quo, total closure, economic and viable
\end{abstract}

This work was carried out with the financial support of the ANR (French National Research Agency) under the ADHOC program, the ERDF (European Regional Development Fund) under the DEPECHE program, the FRB (Fondation Recherche Biodiversité) under the BIO-MER project and IFREMER. We thank all the fishermen who agreed to provide economic data as well as all the observers who collected the other fishery data sets each day. 
strategies are then simulated. They are compared from the viewpoints of both biodiversity preservation and socioeconomic performance, assuming fixed landing prices and fixed costs. We show that fishing outputs, including food supply and fleet profitability, can be sustained on average but a loss of species cannot be avoided.

\section{Introduction}

Marine fishery resources are under extreme pressure worldwide. According to recent studies (Garcia and Grainger, 2005; FAO, 2010), three-quarters of fish stocks are maximally exploited or over-exploited. Moreover, the proportion of marine fish stocks which are intensively exploited is growing. Hence, sustainability is nowadays a major concern raised by international agreements and guidelines to fisheries management. Standard approaches to the sustainable management of fisheries such as MSY (maximum sustainable yield), MEY (maximum economic yield) or ICES ${ }^{1}$ precautionary approaches usually address each exploited species separately (Grafton et al., 2007). These management approaches have not succeeded in avoiding biodiversity loss, over-exploitation and fishing overcapacity worldwide (Hall and Mainprize, 2004). The ecosystem approach for fisheries (EAF) or ecosystem-based fisheries management (EBFM) advocate an integrated management of marine resources to promote sustainability (FAO, 2003). Such a management policy requires first to account for the complexity of ecological mechanisms that encompass community dynamics, trophic webs, geographical processes and environmental uncertainties (habitat, climate). Furthermore, by putting emphasis on sustainability, this type of approach strives to balance ecological, economic and social objectives for present and future generations and to handle a large range of goods and services provided by marine ecosystems (Jennings, 2005), including both monetary and non-monetary values.

However, operationalizing the EBFM approach remains unclear and challenging. It requires models, indicators, reference points and adaptive management strategies. Plaganyi (2007) provides an overview of the main types of modeling approaches and analyzes their relative merits for fisheries assessment in an ecosystem context. Modeling approaches and metrics useful for planning implementing and evaluating EBFM are also discussed in Marasco et al. (2007), with particular emphasis on management strategy evaluation. The use of ecosystem indicators is analyzed by Rice (2000) and Cury and Christensen (2005). In particular, Link (2005) emphasizes the need for a multi-criteria approach to achieve ecological, economic and social objectives.

This article discusses the sustainable management of a multi-species and multi-fleet fishery from an ecosystem-based perspective for the smallscale fishery of French Guiana. Taking an EBFM approach to this case study was challenging. The fishery is characterized by various complex features including a high equatorial fish biodiversity impacted by several

${ }^{1}$ International Council for the Exploration of the Sea, see http:/ / www.ices.dk. 
non-selective fleets and demographic growth which could potentially affect local food demand and consequently the production of this fishery.

\section{Case study}

The continental shelf of French Guiana is a tropical ecosystem under the influence of the Amazon estuary, as is the entire North Brazil Shelf Large Marine Ecosystem (LME) which contains a high biodiversity (Leopold, 2004). With $350 \mathrm{~km}$ of coastline, French Guiana benefits from a $130,000 \mathrm{~km}^{2}$ exclusive economic zone (EEZ) including $50,000 \mathrm{~km}^{2}$ of continental shelf. The coastal fishery operates $16 \mathrm{~km}$ offshore at depths of $0-20 \mathrm{~m}$. Several landing points are spread along the coastline, and this fishery currently involves about 200 wooden boats locally named pirogues $(\mathrm{P})$, canots créoles (CC), canots créoles améliorés (CCA) and tapouilles (T). Pirogues are canoes equipped with an outboard engine, which fish for periods of a few hours essentially in estuaries using ice stored in an old refrigerator. Compared to pirogues, Canots créoles are more adapted to sea navigation. Canots créoles améliorés have cabins and ice tanks which make it possible to fish for several days. Tapouilles are wider boats with a cabin and an inboard diesel engine. The gears used are drift or fixed nets, with mesh sizes between 40 and $100 \mathrm{~mm}$. The type of fleet, the length of gill nets, the number of days spent at sea and the location of fishing activities all have an influence on the quantity of fish landed and on the species composition of the total harvest. Of the numerous coastal species, 30 are exploited and about 15 species, including weakfish, catfish and sharks, represent more than 90 per cent of the production. Annual landings have been estimated at approximately 2,700 tonnes for the past few years, as reported in the Ifremer ${ }^{2}$ Information System (http:/ / www.ifremer.fr/guyane/Chiffres-cles).

The coastal fishery plays an important socioeconomic role for all the small towns along the coastline where more than 90 per cent of the population is located. However, assessment of this fishery only began in 2006 with data collection monitored by Ifremer. Production and fishing effort values are collected on a daily basis at the main landing points by observers from local communities. An exhaustive sampling is performed due to the small number of boats (approximately 200). Seventy five per cent of the fishing activity is observed on a daily basis from January to December. Each year, some 3,600 landings are recorded. For each landing, the production by species is estimated or weighed by the observers or reported by the fishermen. Other information is also collected, such as trip duration, net length and fishing area. Since the boats are under $12 \mathrm{~m}$ in length, fishermen are not obliged to provide this information. The data collection system depends significantly on the fishermen's collaboration. Economic assessment started in 2009 with a survey on production costs and selling prices carried out in the field. The coastal fishery in French Guiana remains largely informal despite: (1) the founding of the French Guiana fishers' cooperative (CODEPEG) in 1982; (2) the implementation of a system of professional

\footnotetext{
${ }^{2}$ French Research Institute for Exploration of the Sea.
} 
licenses in territorial waters by the regional fisheries committee in 1995; and (3) the progressive application of national and European regulations (role of crew, safety inspections of boats, etc.). There is no quota for catches, and no limitation concerning exploited species and their size.

This coastal fishery provides an interesting case study from the perspective of EBF management. The current state of this fishery is usually postulated as safe, and the biodiversity associated with this resource does not seem to be threatened by fishing activity. Nevertheless, the sustainability of the fishery could be threatened by increasing local demand for fish linked to the demographic projections suggesting a 100 per cent increase in the local population over the next 20 years. Consequently, this increasing demand for local fish will affect fishing pressure. The question arises whether both the marine ecosystem and the fishing sector can cope with such changes and contribute to food security.

To examine these issues, this paper proposes a theoretical and empirical modeling of EBFM, using a multi-species and multi-fleet model integrating Lotka-Volterra trophic dynamics and profit functions. The dynamic model is calibrated on a monthly basis with 13 species and four fleets (P, CC, CCA and T) using catch and effort data from 2006 to 2009 derived from the Ifremer fishery information system. Ecological and economic performance of contrasting fishing scenarios including status quo, total closure, economic and viable strategies are examined and compared.

The main contribution of this work is two-fold. First, it proposes for the first time decision support tools for the management of the French Guiana coastal fishery by providing a bio-economic model, analysis and scenarios using time series on catch and fishing effort together with economic parameters. In the broader context of small-scale fisheries, such a bio-economic work relying on a perennial database is new to the best of our knowledge. It is acknowledged that small-scale fisheries are poorly managed due to a lack of tools and data adapted to their complexity, while these fisheries are crucial to sustaining many communities especially in developing or underdeveloped countries (Garcia et al., 2008). The second contribution of this study is to advocate the use of co-viability approaches as a fruitful modeling framework for EBFM and sustainability issues. By accounting for complex and non-linear dynamics in a trophic and multi-fleet context and by addressing biodiversity issues, the paper shows that viability modeling (Bene et al., 2001) can be applied to highdimensional environmental systems. Moreover, this work points out that, by balancing ecological and economic goals with production and food security objectives over the next 40 years, the viability approach is well suited to coping with sustainability due to its multi-criteria perspective and the fact that it takes intergenerational equity into account, as in Péreau et al. (2012).

The paper is structured as follows. Section 3 is devoted to the description of the ecosystem-based model together with bio-economic indicators and scenarios. Section 4 provides the calibration results and the outputs of the different fishing scenarios with respect to biodiversity and socioeconomic indicators. Results are discussed in terms of sustainability, EBFM and management tools in section 5. The final section provides a conclusion. 
Table 1. The 13 selected species representing about $90 \%$ of the catches of the fishery

\begin{tabular}{llc}
\hline Common name & \multicolumn{1}{c}{$\begin{array}{c}\text { Scientific name } \\
\text { Acoupa weakfish }\end{array}$} & $\begin{array}{c}\text { Trophic level } T_{i} \\
\text { (Fishbase) }\end{array}$ \\
\hline $\begin{array}{l}\text { Crucifix sea catfish } \\
\text { Green weakfish }\end{array}$ & $\begin{array}{l}\text { Cynoscion acoupa } \\
\text { Common snooks }\end{array}$ & 4.05 \\
& Cynoscion virescens & 4.35 \\
Sharks & Centropomus parallelus, & 4.03 \\
Centropomus undecimalus & 4.2 \\
Smalltooth weakfish & Sphyrna lewini, Carcharhinus & 4.5 \\
South American silver croaker & Climbatus, Mustelus higmani & \\
Tripletail & Cynoscion steindachneri & 3.25 \\
Gillbacker sea catfish & Lobotes surinamensis & 4.35 \\
Bressou sea catfish & Arius parkeri & 4.04 \\
Goliath grouper & Aspistor quadriscutis & 4.11 \\
Flathead grey mullet & Epinephelus itajara & 3.5 \\
Parassi mullet & Mugil cephalus & 4.09 \\
\hline & Mugil incilis & 2.13 \\
\hline
\end{tabular}

\section{Methods}

The numerical implementations of the model are carried out with the scientific software SCILAB 5.2.2. ${ }^{3}$

\subsection{The ecosystem-based model}

Among the 30 exploited species, 13 were selected for the model as shown in table 1 . These species represent 88 per cent of the total landing from 2006 to 2009. A virtual 14th species which stands for all the other marine producers was added. A potential trophic web (see figure a in the online appendix, available at http:/ /journals.cambridge.org/EDE) was built with these selected species, according to their diet (Leopold, 2004) and their trophic level (table 1).

The ecosystem-based model is a multi-species, multi-fleet dynamic model described in discrete time with a monthly step. The states of the species in the ecosystem-based model are supposed to be governed by a complex dynamic system based on Lotka-Volterra trophic interactions and fishing efforts from the different fleets which play the role of controls in the system. Thus, at each step $t$, the biomass $B_{i}(t+1)(\mathrm{kg})$ of species $i$ at time $t+1$ depends on other stocks $B_{j}(t)$ and fishing efforts $e_{k}(t)$ of fleet $k$ (time spent at sea, in hours) through the relation:

$$
B_{i}(t+1)=B_{i}(t)\left(1+r_{i}+\sum_{\text {species } j=1}^{14} s_{i, j} B_{j}(t)-\sum_{\text {fleets } k=1}^{4} q_{i, k} e_{k}(t)\right)
$$

3 SCILAB (http:/ / www.scilab.org) is an open-source software dedicated to scientific calculus and well suited to the simulation of dynamic systems. 
Here $r_{i}$ stands for the intrinsic growth rate of the population $i$ and $s_{i, j}$ the trophic effect of species $j$ on species $i$ (positive if $j$ is a prey of $i$ and negative if $j$ is a predator of $i$ ). The parameter $q_{i, k}$ measures the catchability of species $i$ by fleet $k$. It corresponds to the probability of a biomass unit of species $i$ being caught by a boat of fleet $k$ during one fishing effort unit. The number of the fleet $k$ from $k=1$ to $k=4$ corresponds respectively to $\mathrm{CC}$, CCA, $\mathrm{P}$ and T.

The catches $H_{i, k}$ of species $i$ by fleet $k$ at time $t$ are thus given by the Schaefer production function:

$$
H_{i, k}(t)=q_{i, k} e_{k}(t) B_{i}(t)
$$

\subsection{Model and calibration inputs}

Values used to define the model parameters came from different sources. Daily observations (catches and fishing efforts) from the landing points all along the coast are available from January 2006 to December 2009. Every month during this 48-month period, for each of the four fleets, fishing effort and catches were identified for the 13 species, for a total of 2,688 observations. The literature (Leopold, 2004) and Fishbase ${ }^{5}$ provided qualitative trophic interactions concerning the sign of the relationship between species and intrinsic growth rates to start the calibration. In particular, only prey-predator and mutual competition relationships are considered in the Lotka-Volterra model, and not symbiotic relationships between species. Initial stocks, catchabilities, trophic intensities and refined intrinsic growth rate values of this ecosystem were estimated through a least square method. This method consisted of minimizing the mean square error between the monthly observed catches $H_{i, k}^{\text {data }}$ and the catches $H_{i, k}$ simulated by the model, as defined by equations (1) and (2):

$$
\min _{B_{0} ; s ; q ; r} \sum_{t=\text { January }} 2006 \sum_{i=1}^{\text {December }} 2009 \sum_{k}^{13}\left(H_{i, k}^{\text {data }}(t)-H_{i, k}(t)\right)^{2} .
$$

Here $\left(B_{0} ; s ; q ; r\right)$ is the set of parameters to identify. $B_{0}=B\left(t_{0}\right)$ is the vector $(14 \times 1)$ of initial stocks $\left(t_{0}=\right.$ December 2005$), s$ the matrix $(14 \times 14)$ of trophic interactions, $q$ the matrix $(14 \times 4)$ of catchabilities, and $r$ a vector $(14 \times 1)$ of intrinsic growth rates.

Several simple biological and productive constraints on parameters were taken into account for the optimization process (equation 3). In particular, several intra-specific interaction coefficients were set to zero (typically B.catfish, F.mullet and P.mullet, $i=10,12,13)$, prey-predator relationships (A. weakfish serve as prey for sharks $s_{5,1}>0$ and sharks are predators of A. weakfish $s_{1,5}<0$ ), common prey relationships (A. weakfish also serve as prey for G. groupers $s_{11,1}>0$ ) and mutual competition (the predators shark and G. grouper prey on each other, $s_{5,11}<0$ and $s_{11,5}<0$ ) were considered

\footnotetext{
${ }^{4}$ Between 2006 and 2009, there were 71 CC, 60 CCA, $45 \mathrm{P}$ and $10 \mathrm{~T}$.

${ }^{5}$ See http://www.fishbase.org.
} 
(table a, online appendix). Some catchability parameters $q_{i, k}$ were also set at zero since some species are not caught by fleets, typically fleet $\mathrm{T}$ (table $\mathrm{b}$, online appendix). The non-linear optimization problem (equation 3) was solved numerically using the Scilab routine entitled 'optim_ga' which relies on an evolutionary (or genetic) algorithm. ${ }^{6}$

\subsection{Model outputs: ecological indicators}

After calibration, ecological and economic indicators were computed to assess the performance of both the ecosystem and the fishery. We first focused on biodiversity indices. Although the choice of a biodiversity metric remains controversial as pointed out in Magurran (2007), we selected the species richness, Simpson and marine trophic indicators provided by equations (4), (5) and (6).

\subsubsection{Species richness}

Species richness $\operatorname{SR}(t)$ indicates the estimated number of species represented in the ecosystem. It is measured by an indicator function based on abundances $N_{i}(t)$, computed as the ratio between the biomass $B_{i}(t)$ and the common weight $w_{i}$ of each species, derived from the Fishbase information system:

$$
\mathrm{SR}(t)=\sum_{i} \mathbf{1}_{\{] 0,+\infty[\}}\left(N_{i}(t)\right), \quad \text { with } N_{i}(t)=\frac{B_{i}(t)}{w_{i}},
$$

where the function $\mathbf{1}_{\{10,+\infty[\}}$ corresponds to the characteristic function ${ }^{7}$ of positive reals. Thus, it is assumed that a species disappears whenever its abundance falls to zero (Worm et al., 2006). It should be noted that rare species have a relatively huge impact on the species richness index.

\subsubsection{Simpson's diversity}

The Simpson index $\mathrm{SI}(t)$ is expressed as:

$$
\mathrm{SI}(t)=1-\sum_{i} f_{i}^{2}(t), \quad \text { with } f_{i}(t)=\frac{N_{i}(t)}{N(t)},
$$

where $N(t)=\sum_{i} N_{i}(t)$. The index SI estimates the probability of two individuals belonging to the same species. The index varies between 0 and 1 .

${ }^{6}$ See http://help.scilab.org/docs/5.3.3/en_US/optim_ga.html for details on 'optim_ga'. A genetic algorithm is a search heuristic that mimics the process of natural evolution. This heuristic is routinely used to generate solutions to nonlinear optimization. Genetic algorithms belong to the larger class of evolutionary algorithms which use techniques inspired by natural evolution, such as inheritance, mutation, selection and crossover. In our case, the genetic algorithm ended up performing better than the usual optimization or calibration algorithms. This type of numerical method has already been used for bio-economic purposes in Mardle and Pascoe (2000), for instance, and for other tropical fisheries in Sathianandan and Jayasankar (2009).

${ }^{7} \mathbf{1}_{\{] 0,+\infty[\}}(x)=1$ if $x>0$; 0 otherwise. 
A perfectly homogeneous community would have a Simpson diversity index score of 1 . Such a metric gives more weight to the more abundant species. The addition of rare species causes only small changes in the value.

\subsubsection{Marine trophic index}

The trophic level indicates the location of a species in a food web, starting with producers (e.g., phytoplankton, plants) at level 0, and moving through primary consumers that eat primary producers (level 1) and secondary consumers that eat primary consumers (level 2), and so on. In marine fishes, the trophic levels vary from two to five (top predators). The marine trophic index $\operatorname{MTI}(t)$ of the ecosystem (Pauly and Watson, 2005) is computed from the trophic level of each species $T_{i}$ (table 1) and their relative abundances $f_{i}$ (see equation 5):

$$
\operatorname{MTI}(t)=\sum_{i=1} f_{i}(t) T_{i}
$$

\subsection{Model outputs: economic indicators}

We now turn to the assessment of the fishing sector through production and profitability values of the fishery provided by equations (7) and (8).

\subsubsection{Food supply}

We first considered the total catches $H(t)$ within the fishery which play the role of food supply:

$$
H(t)=\sum_{k} \sum_{i} H_{i, k}(t) .
$$

This supply must be compared with local food demand, which is expected to increase at an exogenous rate provided by demographic scenarios and projections over the next 20 years.

\subsubsection{Profits}

The profit $\pi_{k}(t)$ of each fleet $k$ was derived from the landings of each species $H_{i, k}$, the landing prices $p_{i, k}$, fixed costs $c_{k}^{f}$, variable costs $c_{k}^{v}$ and the crew share earnings $\beta_{k}$ as follows:

$$
\pi_{k}(t)=\left(1-\beta_{k}\right)\left(\sum_{i} p_{i, k} H_{i, k}(t)-c_{k}^{v} e_{k}(t)\right)-c_{k}^{f} .
$$

Prices, variable costs and fixed costs are those collected for 2008 (table $c$, online appendix). They were assumed to remain unchanged throughout the simulations. Share contract $\beta$ is the salary system commonly used in this fishery for the CCA fleet $(k=2)$ and T fleet $(k=4)$. Crews are remunerated with a share of the landing value minus the variable costs. CC fleet $(k=1)$ and $\mathrm{P}$ fleet $(k=3)$ crews are mostly made up of boat owners, occasionally assisted by a family member. If there is a pay system 
for these fleets, it differs from one owner to another. Hence, to simplify, we set $\beta_{k}=0$ for CC and P fleets and $\beta_{k}=0.5$ for CCA and T fleets. Variable costs $c_{k}^{v}$ include fuel consumption, ice, food and lubricants. Equipment depreciation, maintenance and repairs are incorporated in the fixed costs $c_{k}^{f}$.

The total profit $\pi(t)$ is the sum of profits over all fleets:

$$
\pi(t)=\sum_{k} \pi_{k}(t)
$$

\subsection{Fishing scenarios}

From the calibrated model, scenarios were simulated according to different fishing efforts over 40 years. We distinguished four scenarios: closure (CL), status quo (SQ), economic (PV) and co-viability (CVA). The set of ecological and economic indicators introduced previously were evaluated for these four scenarios.

\subsubsection{The closure scenario (CL)}

The CL scenario corresponds to the implementation of a no fishing zone over the whole French Guiana coastal area:

$$
e_{k}(t)=0, \quad \forall k=1, \ldots, 4 \quad \forall t=t_{1}, \ldots, t_{f}
$$

where $t_{1}$ corresponds to January 2010 and $t_{f}$ to December 2050.

\subsubsection{The status quo scenario (SQ)}

The SQ scenario simulates a steady fishing effort based on the mean pattern of the efforts between 2006 and 2009:

$$
e_{k}(t)=\bar{e}_{k}, \quad \forall k=1, \ldots, 4 \quad \forall t=t_{1}, \ldots, t_{f}
$$

with $\bar{e}_{k}$ representing the mean efforts between 2006 and 2009 for the fleet $k$ as follows:

$$
\bar{e}_{k}=\frac{1}{t_{1}-1} \sum_{t=t_{0}}^{t_{1}-1} e_{k}(t),
$$

where $t_{0}$ and $t_{1}-1$ correspond to January 2006 and December 2009, respectively.

\subsubsection{The economic scenario (PV)}

The PV scenario maximizes the present value of all the future profits aggregated among the fleets $\pi(t)$ defined by equation (9). The present value 
depends on fishing effort patterns as follows:

$$
\operatorname{NPV}(e(.))=\sum_{t=t_{1}}^{t_{f}}(1+\gamma)^{-t} \pi(t)
$$

where $\gamma$ is the discount rate set at $\gamma=3$ per cent. The optimal program underlying the PV scenario is defined by

$$
\max _{e_{k}(t)} \operatorname{NPV}(e(.))
$$

In this scenario, it is assumed that the fishing efforts $e_{k}(t)$ rely on a control strategy that can be adapted every 5 years. ${ }^{8}$ In other words, eight decisions $\left(e_{k}\left(t_{1}\right), e_{k}\left(t_{2}\right), \ldots, e_{k}\left(t_{8}\right)\right)$ are available for each fleet $k$ as follows:

$$
e_{k}(t)=\left\{\begin{array}{cc}
e_{k}\left(t_{1}\right) & \text { for } t=t_{1}, \ldots, t_{1}+60 \\
e_{k}\left(t_{2}\right) & \text { for } t=t_{2}, \ldots, t_{2}+60 \\
\vdots & \\
e_{k}\left(t_{8}\right) & \text { for } t=t_{8}, \ldots, t_{8}+60
\end{array}\right.
$$

where $t_{1}$ and $t_{n}=t_{n-1}+60$, for $n=2$ to 8 , are decisive months.

The optimal effort $e_{k}(t)$ solutions of the intertemporal program (equation 11) were approximated numerically by again using an evolutionary algorithm, in particular the routine entitled 'optim_ga' in Scilab.

\subsubsection{The co-viability scenario (CVA)}

The purpose of the CVA scenario is to provide a satisfactory balance over time between fleet profitability, biodiversity and local food demand. Thus, viable levels of fishing effort aim at complying with the bio-economic constraints below:

- A profitability constraint: $\pi_{k}(t) \geq 0, \forall t=t_{1}, \ldots, t_{f}, \forall k=1, \ldots, 4$

- A species richness constraint: $\operatorname{SR}(t) \geq 11, \forall t=t_{1}, \ldots, t_{f}$

- A food security constraint: $H(t) \geq H(2009) \cdot(1+d)^{t}, \forall t=t_{1}, \ldots, t_{f}$,

where $d$ stands for the growth rate of the population. The profitability constraint holds for each fleet separately and not for the aggregated rent as

8 A refined time decomposition for fishing intensities (for instance, a one-year time step) would have improved the analysis by capturing a broader intertemporal flexibility in fishing strategy. However, it would have required very demanding computation times. Steady efforts over 5 years as imposed here capture rigidity and inertia mechanisms in behaviors which may occur in reality. We plan to expand the time step for decisions in future models. 
in the PV scenario. Concerning the biodiversity constraint, no co-viability path maintaining the whole set of 13 species was exhibited. This explains why the species richness required was relaxed to only 11 species. Finally, the food security constraint assumed an increase in the local fish demand at the annual rate of $d=3$ per cent, according to the demographic scenario which predicts a doubling of French Guiana's population by 2030 (INSEE, 2011). Moreover, it was assumed that fish species can be substituted, in the sense that a drop in the consumption of one species can be compensated for by a rise in the consumption of other species.

Following DeLara and Doyen (2008) and Doyen and De Lara (2010), viable efforts for the CVA scenario were obtained by maximizing the following criterion:

$$
\max _{e_{k}(t)} \prod_{t=t_{1}}^{t_{f}} \mathbf{1}_{\{[0,+\infty[\}}\left(\pi_{k}(t)\right) \mathbf{1}_{\{] 0,+\infty[\}}(\operatorname{SR}(t)-11) \mathbf{1}_{\{[0,+\infty[\}} \cdot\left(H(t)-H(2009) \cdot(1+d)^{t}\right)
$$

where again, efforts $e_{k}(t)$ are meant to be control strategies that can change every 5 years as in equation (12), and $\mathbf{1}_{\{] 0,+\infty[\}}$ represents the characteristic function on positive reals. The numerical method again relies on the evolutionary optimization routine.

\subsection{Sensitivity analysis and uncertainty margins}

A sensitivity analysis was carried out to evaluate the role played in the bio-economic outputs by the different calibrated parameters (tables $a$ and $b$, online appendix). To achieve this, we ran additional simulations based on the SQ scenario. Given the large number of parameters, we limited the sensitivity analysis by simultaneously perturbing all the parameters of the same group, i.e., initial stocks $B_{0}$, catchabilities $q$, trophic intensities $s$ and intrinsic growth rates $r$. For each group of estimated biological parameters, a noise ranging from -10 per cent to +10 per cent of the calibrated values was added to the parameters. The relative differences in bio-economic outputs including average catches per annum $\bar{H}=\frac{12}{t_{f}-t_{1}} \sum_{t=t_{1}}^{t_{f}} H(t)$, net present value (NPV) and specific richness $\operatorname{SR}\left(t_{f}\right)$ were computed. Sensitivity analysis was also carried out to examine the impact of the choice of time horizon on the outputs. Therefore, other simulations with the SQ scenario were performed, increasing the simulation length $t_{f}$ from December 2060 to December 2100. The corresponding bioeconomic results were compared with those obtained with $t_{f}=$ December 2050

In line with this, in order to assess the reliability of the outputs for each effort scenario, simulations were replicated 400 times by introducing uncertainties in the estimated parameters $\left(r, s, q, B_{0}\right)$. For each simulation, a noise ranging from -10 per cent to +10 per cent of the calibrated values was again randomly added to the parameters. 

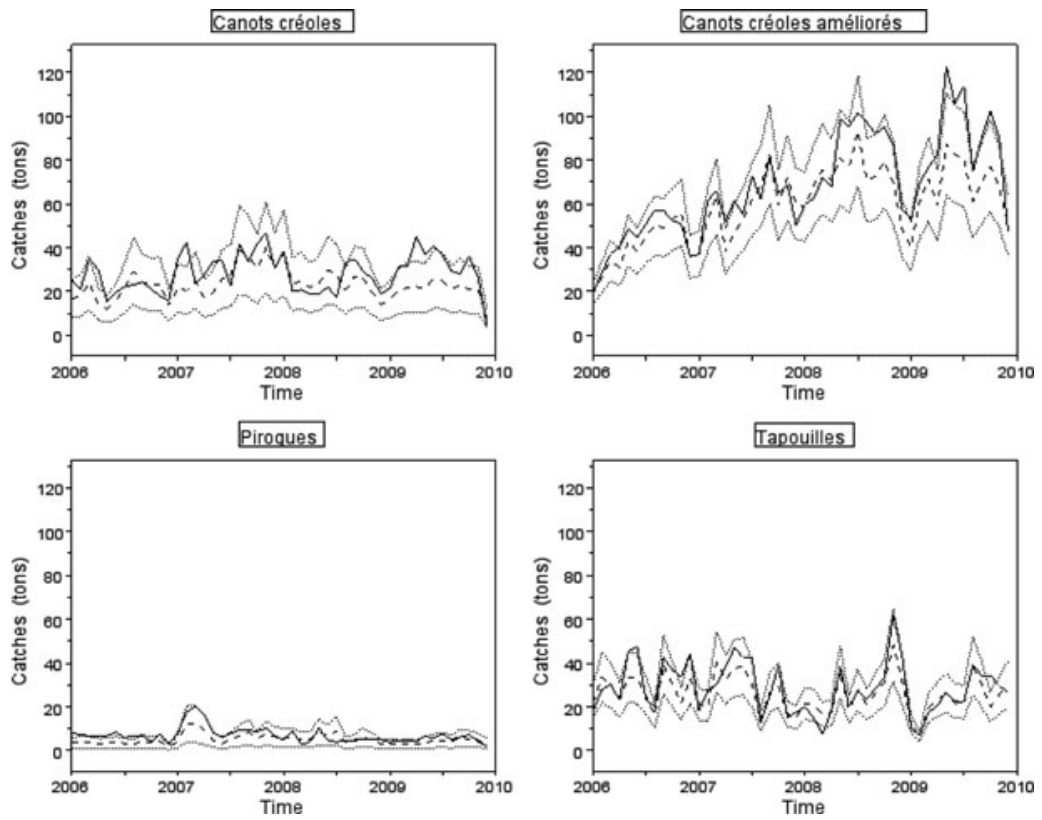

Figure 1. Comparison by fleet $k$ between historical catches $\sum_{\text {species } i} H_{\text {species } i, k}^{\text {data }}(t)$ (solid lines) and simulated catches $\sum_{i} H_{i, k}(t)$ (dashed lines), with the confidence intervals at 95\% (dotted lines)

\section{Results}

4.1. Calibration and sensitivity results

Figure 1 presents the historical and simulated catches by fleet, with 95 per cent confidence intervals. For each fleet $k$, confidence intervals ${ }^{9}$ were computed from the mean relative errors $\Delta_{k}$ between observed and simulated catches from January 2006 to December 2009,

$$
\Delta_{k}=\frac{1}{48} \sum_{t=t_{0}}^{t_{1}-1}\left|\frac{H_{k}^{\text {data }}(t)-H_{k}(t)}{H_{k}(t)}\right|,
$$

where $H_{k}(t)=\sum_{i} H_{i, k}(t)$ stands for catches by fleet $k$ at time $t$ over the whole 13 species $i$. The mean relative errors equal ${ }^{10} \Delta_{1}=0.259$ for CC, $\Delta_{2}=0.13$ for CCA, $\Delta_{3}=0.354$ for $\mathrm{P}$ and $\Delta_{4}=0.176$ for $\mathrm{T}$.

${ }^{9}$ For each month $t, 95$ per cent confidence intervals are $\left[1-1.96 * \Delta_{k}, 1+1.96 *\right.$ $\left.\Delta_{k}\right] * H_{k}^{\text {data }}(t)$.

10 The relative errors for the Euclidean or quadratic norm, $\Delta_{k}^{*}=$ $\sqrt{\frac{1}{48} \sum_{t=t_{0}}^{t_{1}-1}\left(\frac{\left(H_{k}^{\text {data }}(t)-H_{k}(t)\right)}{H_{k}(t)}\right)^{2}}$, yields: $\Delta_{1}^{*}=0.308$ for CC, $\Delta_{2}^{*}=0.151$ for CCA, $\Delta_{3}^{*}=0.414$ for $\mathrm{P}$ and $\Delta_{4}^{*}=0.257$ for $\mathrm{T}$. 

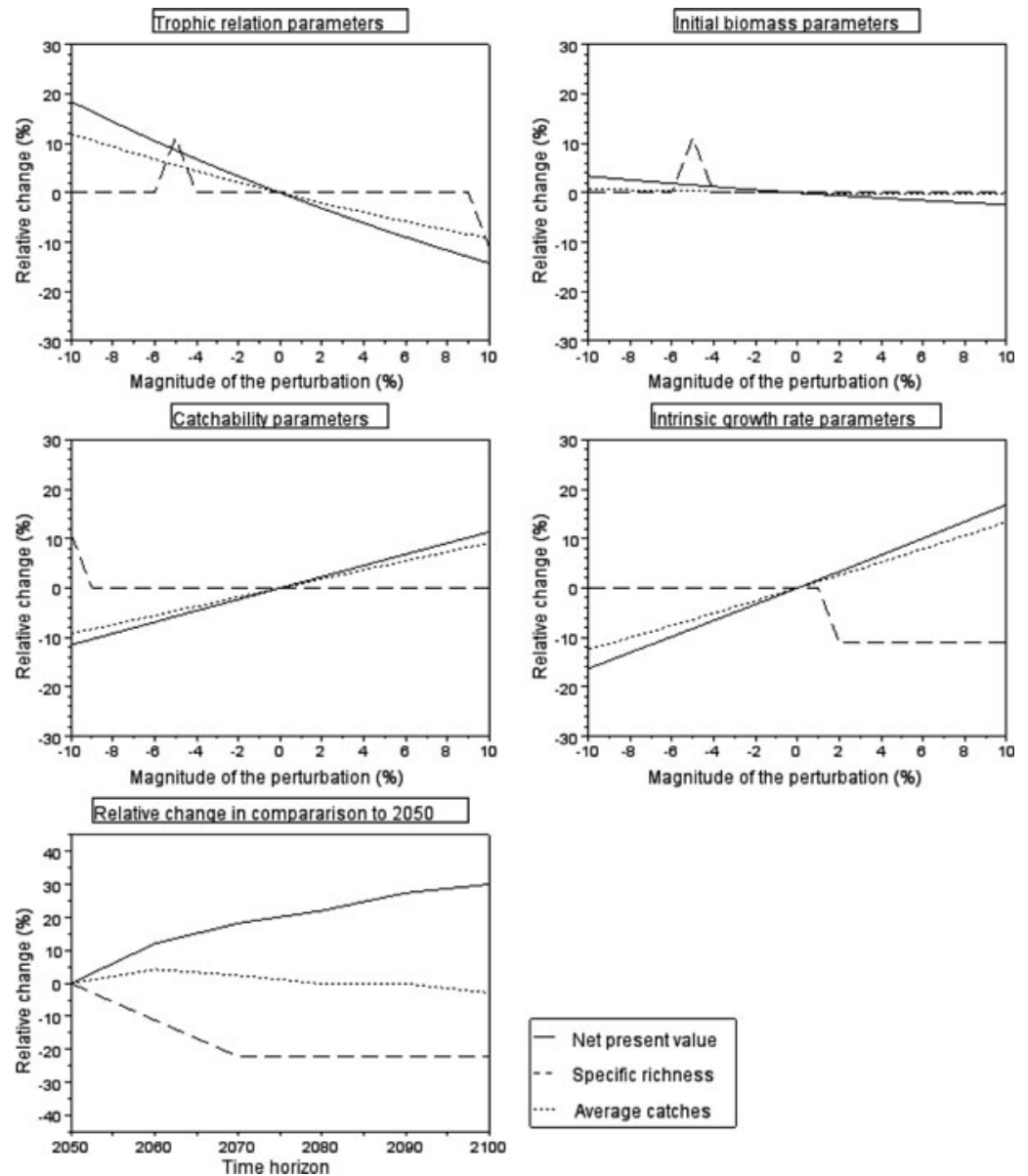

Figure 2. Relative changes of NPV (solid line), average annual catches $\bar{H}$ (dotted line), species richness $S R\left(t_{f}\right)$ (dashed line), according to variations in input parameters by $1 \%$ increments from $-10 \%$ to $+10 \%(a, b, c$ and $d)$, and time horizon (e). The baseline is status quo scenario $S Q$

Figure 2 displays the sensitivity results. They stress the fact that the parameters with the greatest impact were intrinsic growth rates $r_{i}$ and trophic interactions $s_{i j}$. The relative changes in NPV and average catch outputs appear to be approximately linear functions of the perturbations with slopes between 0 and 1.8 highlighting bounds for the marginal effects of the parameters. In particular, the impact of initial biomasses was small since the relative changes were less than the perturbation magnitude for these biomasses. Trophic intensities and intrinsic growth rates were the inputs for which a perturbation entailed larger relative changes in the outputs. The non-linear nature of the species richness index is captured by the staircase shape of the relative change as well as the peaks observed. Moreover, the relative changes in bio-economic outputs in comparison to the 2050 
time horizon show a reduced impact of the temporal target in the results. In particular, the NPV is not affected by a change of horizon mainly because of the discount involved. Of interest is the fact that species richness is stabilized after 2070. The average annual catches continue to rise with the time horizon, which emphasizes the fact that overall fishery production does not collapse after year 2050 and could even be enhanced.

\subsection{Scenarios, effort levels}

Figure 3 displays the effort multipliers $\frac{e_{k}(t)}{\bar{e}_{k}}$ by fleet for each fishing scenario. These effort multipliers are based on the comparison between effort $e(t)$ and the mean pattern of efforts $\bar{e}_{k}$ between 2006 and 2009 defined in equation (10). The SQ effort multiplier is equal to one, as expected. It turns out that the PV scenario induces the largest decrease in fishing efforts to maximize the present value of aggregated rent. In particular, the PV scenario implies stopping fishing activity for the CC and CCA fleets during the entire simulation period. With regard to the $\mathrm{T}$ fleet, fishing effort is increased in the first two decades of the simulation and stopped in the last decade. By contrast, the fishing effort of the P fleet follows an opposite pattern. Effort is nil during the first two decades of the simulation and is increased after 2030. The multiplier for the T fleet reaches 2.4 in the first part of the simulation, while for the P fleet, multipliers range from 2.2
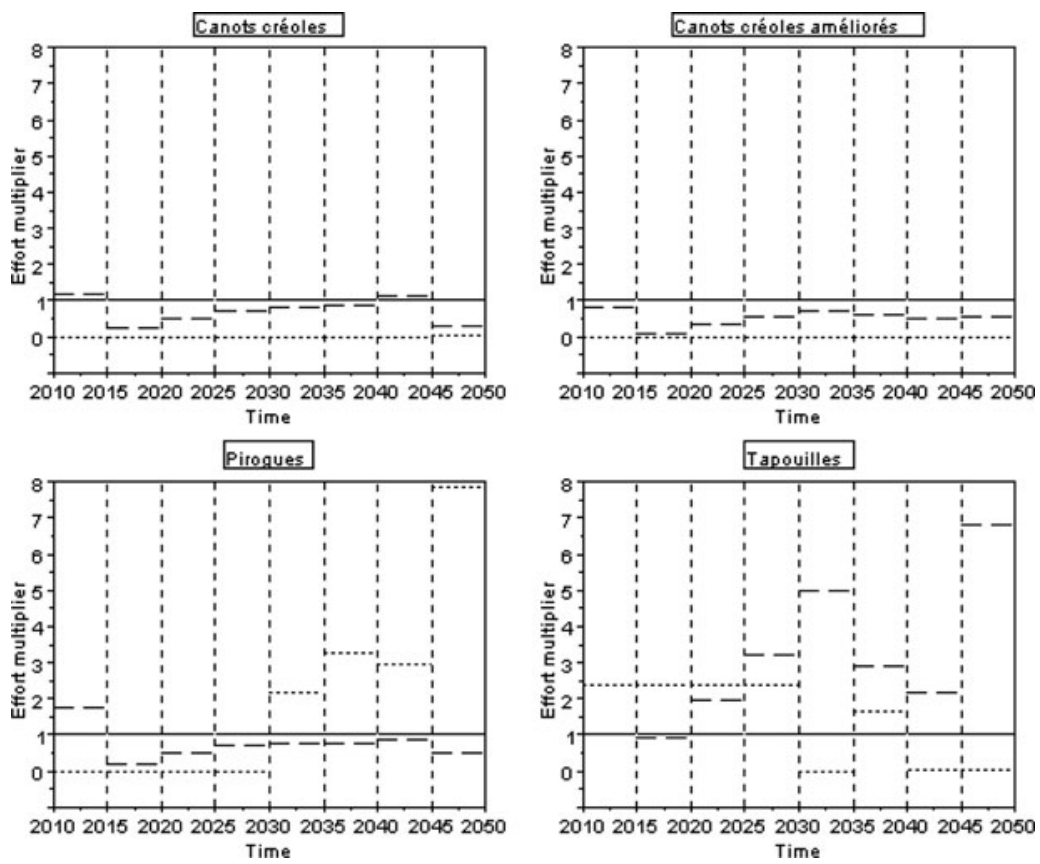

Figure 3. Fishing effort multiplier $u_{k}(t)=\frac{e_{k}(t)}{\overline{e_{k}}}$ by fleet and scenario: SQ (solid line), economic PV (dotted line), co-viability CVA (dashed line) 
to 7.8 for the second part of the simulation. In contrast, the CVA scenario guarantees an activity for every fleet throughout time. On average, its effort level is lower than the baseline SQ except for the T fleet, which exhibits an effort multiplier ranging from 0.9 to 6.8. The average multiplier of the viable strategy is 0.7 for CC, 0.51 for CCA, 0.75 for $\mathrm{P}$ and 3.0 for $\mathrm{T}$.

\subsection{Ecological results}

Trends in the evolution of species richness according to the scenarios are plotted in figure 4 (marine trophic and Simpson diversity evolutions are available in figures $b$ and $c$ in the online appendix). The 'mean' trajectories induced by the calibrated values are plotted together with margin errors of 400 simulations derived from the perturbation of the parameters selected randomly in [ -10 per cent; +10 per cent]. First it appears that a loss of species occurs for every scenario, as species richness decreases in every case except in the CL scenario, as expected (at least when the parameters are not perturbed). In other words, implementing a no fishing zone should maintain species diversity. By contrast, the baseline SQ scenario leads to the worst result in terms of diversity loss. Species richness ranges from 11 to 8 at the end of the simulation period. The mean simulation provides nine species at the end and species like Crucifix catfish, Common snook, Silver croaker and Bressou catfish disappear. With the PV scenario, both Crucifix catfish and Bressou catfish collapse. The final state of species richness with the CVA scenario is qualitatively identical to the PV scenario since 11 species remain at the end while the same species disappear. From mean estimated
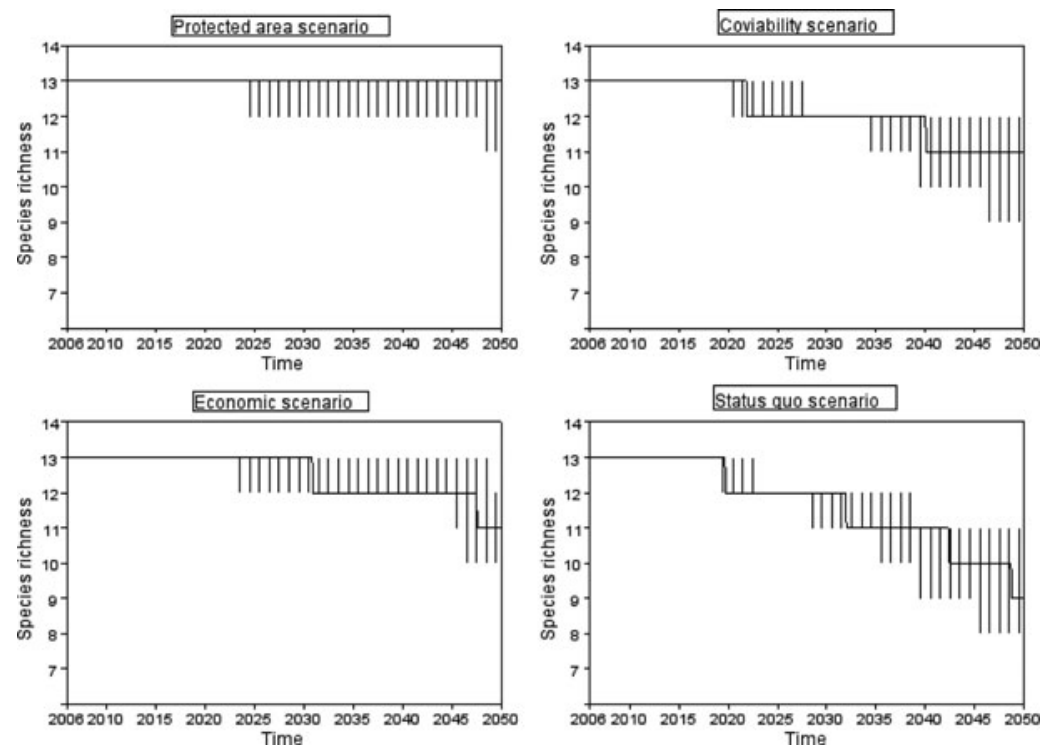

Figure 4. Species richness $S R(t)$ evolution by scenario (solid lines), with uncertainties (vertical lines) 
parameters, two species (Crucifix catfish and Bressou catfish) become extinct in the SQ, CVA and PV scenarios, but the extinction periods are not identical: species extinctions are delayed in proportion to the reductions in effort level. Extinction periods of these two species correspond to years 20202032 for the SQ scenario, 2022-2040 for the CVA scenario and 2031-2047 for the PV scenarios respectively.

The trajectories of the two other biodiversity indices are more complex and difficult to interpret. The species abundances change considerably in the simulation period. In particular, a major change occurs around 2015 for all ecological indicators when certain species start to decline. This decrease is illustrated by the decline in catches between 2015 and 2020 for the SQ scenario (figure 5). At the start of the mean simulation, the total biomass is not equally distributed among the species with $\mathrm{SI}=0.5$, and the marine ecosystem is dominated by species with a low trophic level, MTI $=2.5$. At the end of the mean simulation, for all scenarios, diversity indices are better than those at the beginning (SI ranges from 0.61 to 0.77 , MTI from 2.79 to 3.08 , according to the scenario).

The impact of uncertainties is significant, as the ecological indices appear volatile in particular for the last years. This indicates that the results should be considered with caution.

\subsection{Economic results}

Catches and profits for the SQ, PV and CVA scenarios are plotted in figures 5-8. The main biomass changes in years 2015-2020 also affect the catches and profits. The SQ scenario seems economically viable in terms of profitability, as annual profits are positive during almost the entire period for all fleets. However, exceptions occur for the CC and CCA fleets in the first years of the simulation and for the P fleet in the 2010-2011 and 2026-2034 periods. Not surprisingly, the PV scenario yields the highest cumulative discounted profit, between $€ 1.125$ and 2.399 billion vs. $€ 123.2-$ 203.3 million vs. for the SQ scenario and €84.7-239.9 million for the CVA scenario. The greatest fishing activity occurs in the second part of the simulation for the $\mathrm{P}$ fleet. One explanation can be found in the high value of the selling prices for this fleet (table c, online appendix). On average, the CVA scenario provides positive annual profits for each fleet throughout the simulation despite the fact that the CVA fishing effort is lower than the SQ effort. However, as the CVA scenario effort levels were computed from the mean estimated parameters, the uncertainties may alter the profitability in certain years.

Comparison of the fish demand curve with the supply curves by scenario (figure 5) shows that yield levels may differ broadly from local fish demand projections. In particular, for a period of several years, the mean production is lower than the fish demand ${ }^{11}$ except for the mean CVA scenario, as expected. In the same vein, the mean cumulative supply over 40 years of the CVA scenario with $H=\sum_{t} H(t) \approx 262$ Ktons is the

${ }^{11}$ It should be pointed out that prices are fixed and then do not clear the market. This assumption could be relaxed in future work. 

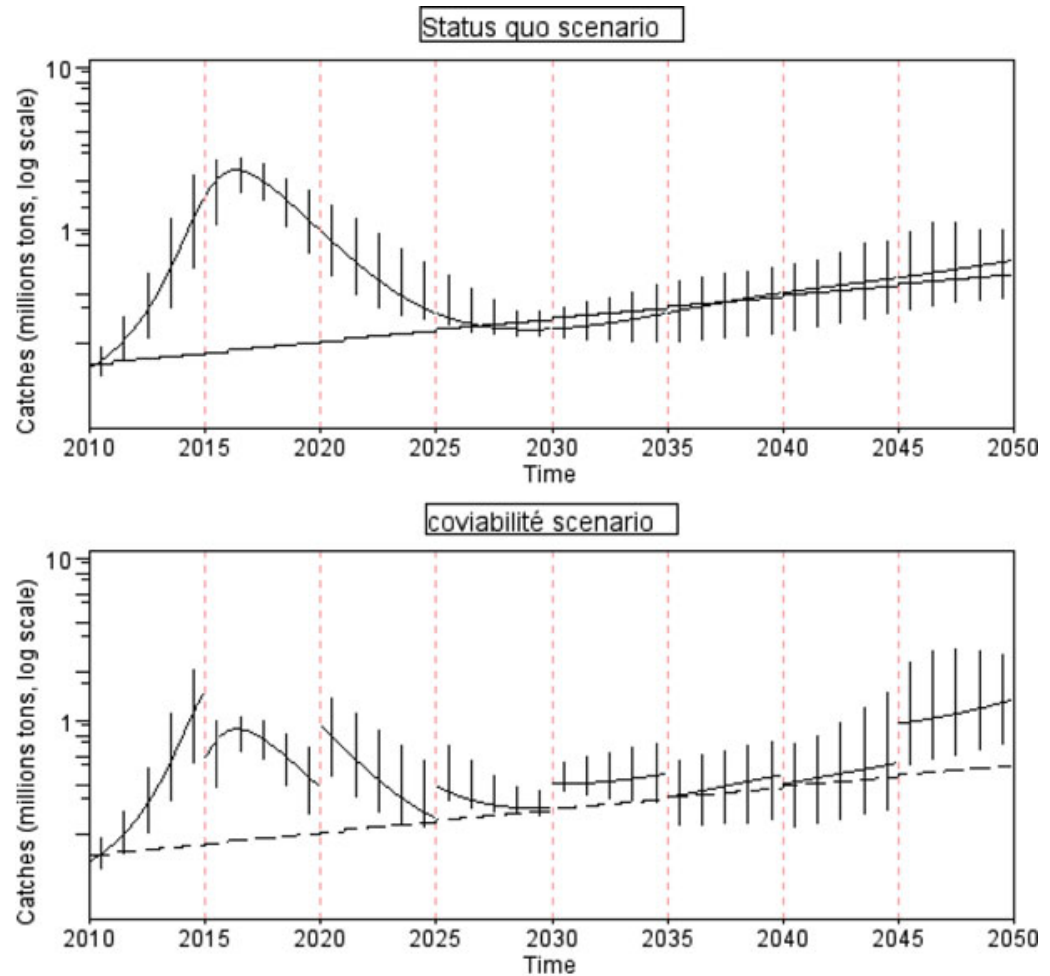

Economic scenario

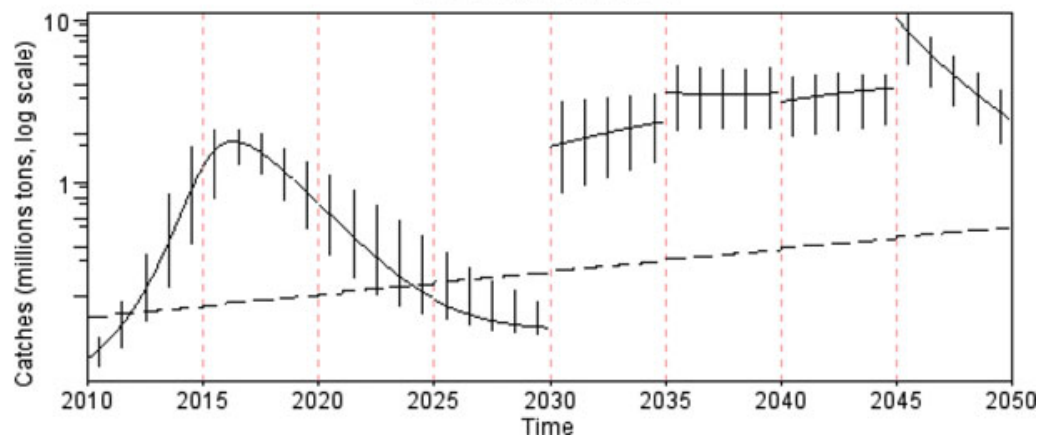

Figure 5. Total catches $H(t)$ by scenarios (solid lines) vs. local fish demand (dashed line), with uncertainties (vertical lines)

closest to the cumulative fish demand of 144 Ktons as compared to the SQ and PV scenarios with $H=284$ and $H=986$ Ktons respectively. However, it also appears that the food security constraint of the CVA scenario may be violated during some years when uncertainties are taken into account. 

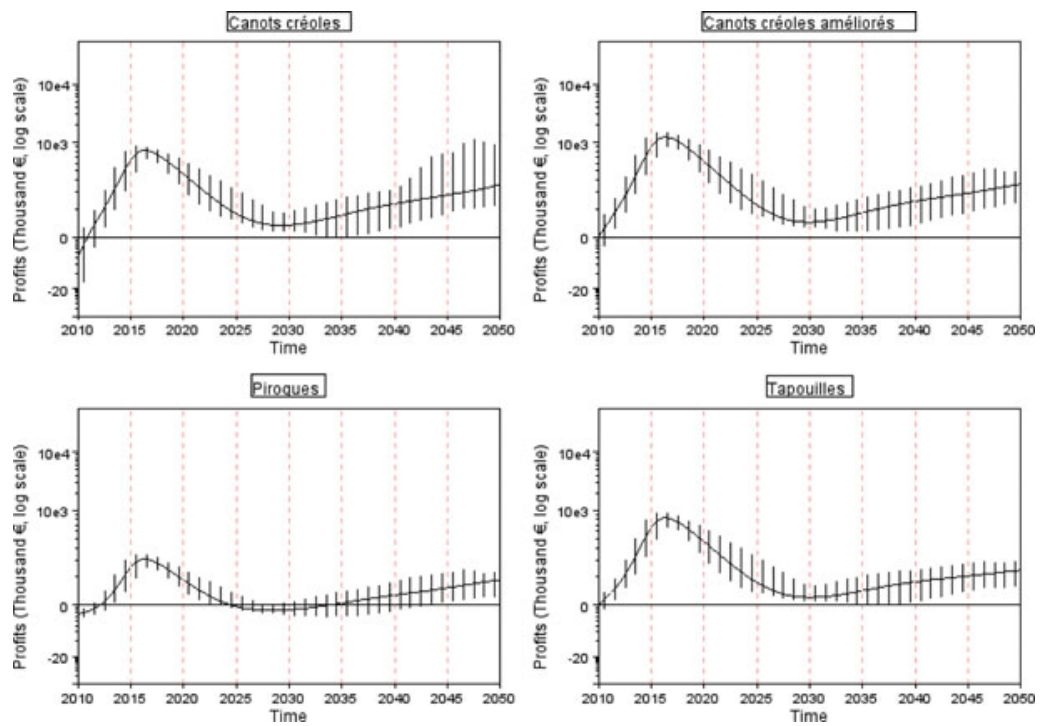

Figure 6. Profit $\pi_{k}(t)$ by fleet for the $S Q$ scenario (solid lines), with uncertainties (vertical lines). The dotted line stands for profitability threshold
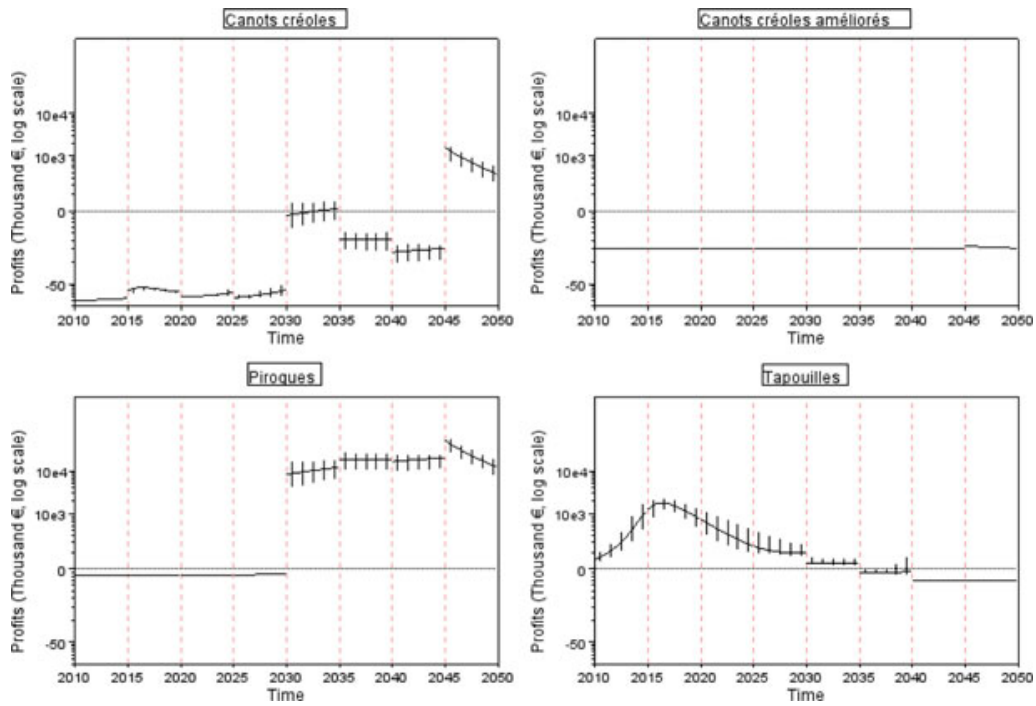

Figure 7. Profit $\pi_{k}(t)$ by fleet for the PV scenario (solid lines), with uncertainties (vertical lines). The dotted line stands for profitability threshold

\section{Discussion}

5.1. Co-viability as a step towards sustainability

Let us first analyze our results in terms of sustainability. Obviously, a total fishery closure is not a satisfactory solution either economically or socially 

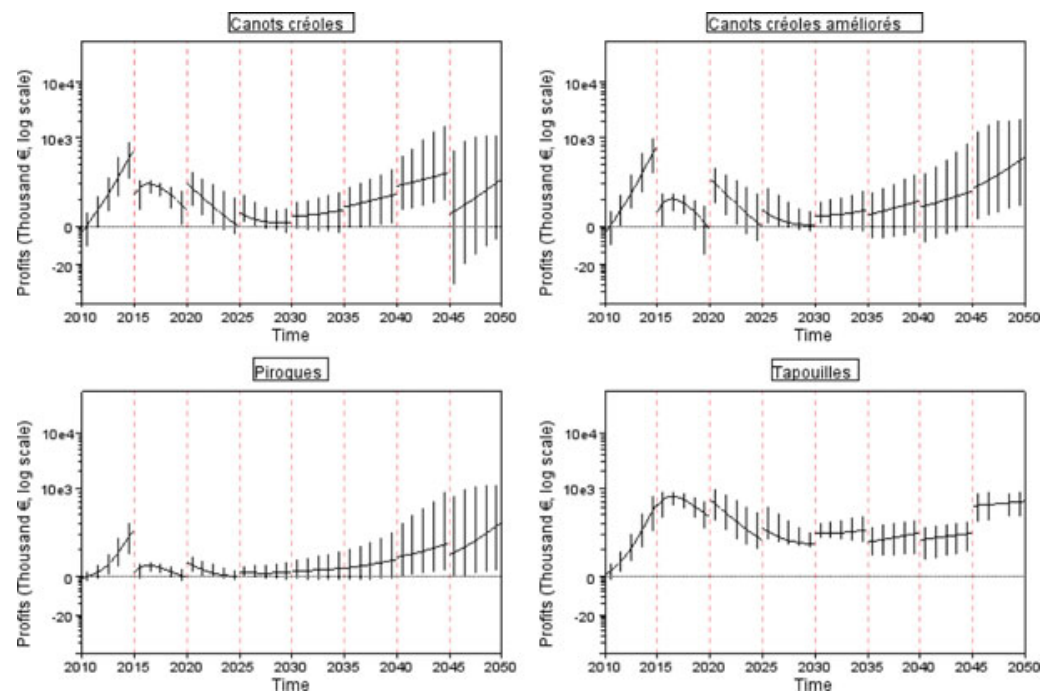

Figure 8. Profit $\pi_{k}(t)$ by fleet for the CVA scenario (solid lines), with uncertainties (vertical lines). The dotted line stands for profitability threshold

in terms of jobs, income and food consequences. It turns out that maintaining constant efforts through the SQ scenario is also not a suitable and sustainable strategy. In fact, aside from the fact that the CC and P fleets do not realize any profit in the first years, the SQ scenario does not satisfy the constraint of local consumption from years 2028-2038 in the mean regime and provides the worst performance for species richness. The calibration context can partially explain the negative profits of these fleets at the beginning of the simulation. Indeed, economic data are based on year 2008 which was unusual: fuel prices reached a record and thus production costs rose considerably. More generally, the low prices at first sale and the production costs did not allow every vessel to generate profits. Not surprisingly, the largest cumulative discounted profit and the most important fish supply are obtained with the PV scenario. However, this scenario may not be socially acceptable since profits are not evenly distributed between fleets over time. This happens because this scenario imposes that the CC and CCA fleets cease their activities, inducing negative profits for these fleets due to fixed costs (figure 7). That some fleets exhibit negative profits is consistent from the social planner's point of view underlying the PV approach, since aggregated profits are optimized by favoring the most efficient fleets. A better balance between biodiversity and socioeconomic performance can be reached with the CVA scenario, at least on average. Although two species disappear, this scenario appears to be the best compromise: it allows annual positive mean profits for every fleet and satisfies local consumption during the 40 years of simulation. However, the variability of outputs due to noise in parameters suggests that a stochastic or robust approach would be fruitful to guarantee this viability in an uncertain context. 
In addition to analysis on the case study, this work advocates an integrated and multi-criteria approach. A wide range of stakeholders are involved in fisheries, including: industrial, artisanal, subsistence and recreational fishermen; suppliers and workers in allied industries; managers, environmentalists, biologists, economists; public decision makers and the general public. Each of these groups has an interest in particular outcomes from fisheries, and the outcomes that are considered desirable by one stakeholder may be undesirable for another group (Hilborn, 2007). Considering this multi-dimensional nature of marine fisheries management is a way to guarantee the reasonable exploitation of aquatic resources, allowing the creation of conditions for sustainability from economic, environmental and social viewpoints. The present work is fully in line with these considerations. First, of interest is the use of bio-economic models and assessments articulating ecological and socioeconomic processes and goals as in Bene et al. (2001); Doyen et al. (2012); Péreau et al. (2012). Moreover, by focusing on sustainability and viability, the present model exhibits management strategies and scenarios that account for intergenerational equity. As emphasized in Martinet and Doyen (2007) and DeLara and Doyen (2008), viability is closely related to the maximin (Rawlsian) approach with respect to intergenerational equity. In this respect, the CVA strategy turns out to be a promising approach.

\subsection{Co-viability as a step towards EBFM}

Several authors have proposed the viability approach as a new, innovative and well-suited modeling framework for EBFM (Cury et al., 2005; Doyen et al., 2012). They argue that the viability approach, especially coviability, is relevant in handling EBFM issues because it may simultaneously account for dynamic complexities, bio-economic risks and sustainability objectives balancing ecological, economic and social dimensions for fisheries. In particular, Cury et al. (2005) and Doyen et al. (2007) show how the approach can potentially be useful for integrating ecosystem considerations for fisheries management. Mullon et al. (2004), Bene and Doyen (2008) and Chapel et al. (2008) emphasize the ability to address complex dynamics in this framework. The computational and mathematical modeling methods proposed in this paper through the CVA strategy are motivated by a similar prospect. One major advantage of the co-viability approach is the fact that the viability framework is dynamic and thus makes it possible to capture the interactions and co-evolution of marine biodiversity and fishing. The dynamics can potentially include complex mechanisms such as trophic interactions, competition, metapopulation dynamics or economic investment processes. Here the focus is both on trophic and technical interactions through a multi-fleet and multi-species context as in Doyen et al. (2012).

Projections over 40 years for different fishing scenarios highlight the complexity of mechanisms at play, particularly their non-linearity. With regard to this point, the trajectories of ecological indicators are representative and should not be interpreted separately. The species richness for the CL scenario can be sustained, meaning that all species are present at the end of the mean simulation. However, the Simpson and marine trophic 
indices reveal that species abundances change over the simulation period, even more when uncertainties on estimated parameters are considered. Diversity index (SI, MTI) values at the end of the mean simulation lead to the following findings: (1) total biomass is better distributed among species and (2) the species with a high trophic level are better represented. Thus, the effects of fishing on the species can be deduced: fishing leads to ecosystem specialization.

\subsection{Decision support for the French Guiana small-scale fishery}

Small-scale fisheries remain poorly managed because of their heterogeneity, difficulties in getting consistent and perennial data and the lack of regulation tools. The problem is more acute in a tropical context with a high-level informal activity and high biodiversity with low stock biomass (this is typically valid for reef ecosystems). In French Guiana, waters are very turbid and productive due to the proximity of the Amazon river. There are no reefs, but biodiversity is high, as is biomass. The bio-economic database monitored from 2006 with the help of local communities who collected time series data offers the opportunity to go a step further towards building management tools. Since the decline of the French Guiana industrial shrimp fishery (Chaboud et al., 2008), the coastal fishery has become a sector with a high potential for development. In 2008, coastal fishery production was higher than shrimp and red snapper landings. However, as previously stated, there is no quota for catches, and no limitation concerning exploited species and their size. Regulation tools are derived from commonly used national and European fisheries management systems. These standards concern the gear selectivity (mesh size) and the global size of the fleet through total engine power and total vessel capacity. However, due to the lack of studies on the stock status for the main exploited species, rules relating to overall fleet size have not been adapted to the changing level of fish stocks. The only aim of the current management strategy is to prevent fishing activity by unauthorized boats. The present bio-economic study should contribute to the design of more scientific and relevant assessments and regulations for both the marine ecosystem and this small-scale fishery. At this stage, we would like to point out the methodological interest of sustaining the fishery information system to achieve such goals.

Fishing scenario outputs show that fishing performance, including food supply and profitability of fleets, can be increased or sustained. In particular, this suggests that the marine ecosystem and the fishing sector could cope with food demand and contribute to food security. This could have positive consequences for the development of French Guiana, since the coastal fishery plays an important socioeconomic role for the small towns along the coastline where more than 90 per cent of the population is located. However, there is a risk of losing fish biodiversity due to fishing pressure. This loss of biodiversity could potentially alter some ecosystem services (not taken into account in the current model) and the outcomes of the fishery itself in the long run. Thus, some fish stocks should be evaluated more specifically in order to anticipate their depletion (Crucifix catfish, Bressou catfish). Depending on the endangered stocks, conservation measures for the productive and reproductive capacities of these stocks should 
be taken. This could be achieved by banning fishing in nursery areas or providing incentives for using more selective fishing techniques. In this way, the co-viability approach could enable long-term management of the French Guiana coastal fishery. The CVA scenario suggests that such a multifunctional sustainability would be maintained with a small increase in the T fleet's effort and a relative reduction for the other fleets (CC, CCA or P). This management strategy entails implementing limitations on fishing effort. Nevertheless, this scenario may remain attractive for the different stakeholders involved since the profitability constraint for each fleet, the species richness constraint and the food security constraint are all satisfied. In this sense, the CVA strategy could be potentially operationalized with the fishermen's cooperation.

\section{Conclusion}

This work provides a bio-economic model and analysis for the coastal fishery in French Guiana. It relies on a multi-species and multi-fleet model integrating Lotka-Volterra trophic dynamics and profit functions. The dynamic model is calibrated using data from the Ifremer fishery information system. Ecological and economic performance of contrasting fishing scenarios including status quo, total closure, economic and viable strategies are compared. The major contribution of the paper is two-fold. First, it proposes for the first time decision support tools for the management of the small-scale fishery in French Guiana. Small-scale fisheries are poorly managed due to a lack of tools and data, although these fisheries are crucial to sustaining many communities especially in developing or underdeveloped countries (Garcia et al., 2008). The present work emphasizes the interest of bio-economic models which rely on a perennial database in this context of small-scale fisheries. The second contribution of this study is to advocate the use of viability approaches as a relevant modeling framework for EBFM and sustainability issues. Such sustainability is known to be difficult to achieve because economic, social and ecological goals can contradict each other (Pitcher, 2001). The paper points out that, by balancing ecological and economic goals with production and food security objectives over several decades, the viability approach is well suited to address sustainability. By accounting for complex and non-linear dynamics and by addressing biodiversity issues, the paper also shows how viability modeling can be applied to high-dimensional environmental systems. More generally, the present work suggests that adopting the viability method would enable other objectives of the EBFM approach to be taken into account. For instance, fisheries are urged to transform their practices progressively, to favor ecofriendly technologies, to reinforce the quality and reliability of products and services and to create jobs. New management policies integrating all these dimensions in accordance with public goals need to be defined, especially in this kind of small-scale coastal fishery (Blanchard and Maneschy, 2010).

Due to the uncertainties underlying the calibrated parameters, the results of this paper should be interpreted with caution. The reliability 
of some parameters needs to be reinforced to obtain a more accurate model. Up to now, only shrimp and red snapper fisheries have been widely studied in French Guiana. It turns out that certain parameters are estimated from Fishbase or from the literature. Consequently, it would be fruitful to integrate more values from local field studies dedicated to this ecosystem (for instance, intrinsic growth rates and trophic levels). Stomach content data analysis would also improve trophic interaction evaluations. Similarly, as landings are computed from catchabilities and initial stocks, it would be important to obtain a refined estimation of these parameters. These uncertainties suggest that a more robust approach based on stochastic viability methods should be used (Doyen and De Lara, 2010; Doyen et al., 2012). Doing so would significantly strengthen the robustness of the outcomes and assertions of this dynamic complex model. At this stage, we would like to point out the advantage of sustaining the Fishery Information System with the help of local communities.

Furthermore, the ecosystem-based model is based on simplified dynamics. In fact, species in French Guiana's coastal ecosystem present different trophic levels (from 2.01 to 4.35), leading us to consider predator-prey relationships between the 13 species selected in the model. We used a basic Lotka-Volerra model because of the high number of species considered and the lack of biological data. Indeed, other models such as an individualbased model would have required us to calibrate even more biological parameters. In future work, we plan to refine the Lotka-Volterra model by adding a predator saturation effect, such as the Holling functional response (Holling, 1959), when preys are abundant.

Many other issues could be addressed in future work. From an economic and social viewpoint, taking into account the demand mechanism and endogenous prices is necessary to improve the predictions of the model. A next step would be to integrate social indicators such as employment level and job satisfaction to evaluate the scenarios with regard to social performance (Blanchard and Maneschy, 2010). From an ecological perspective, it would be interesting to extend the number of species in order to include the effects of fishing activities on the dynamics of other species (such as mammals, turtles or birds) and on plankton dynamics. In line with this, comparisons with the Ecopath (EwE) approach could be informative. Another interesting goal would be to include the effects of climatic changes, for instance sea surface temperatures (Thébaud and Blanchard, 2011). Finally, a spatial extension of this model could also be considered to integrate, for instance, the effects of protected areas.

\section{References}

Bene, C. and L. Doyen (2008), 'Contribution values of biodiversity to ecosystem performances: a viability perspective', Ecological Economics 68: 14-23.

Bene, C., L. Doyen, and D. Gabay (2001), 'A viability analysis for a bio-economic model', Ecological Economics 36: 385-396.

Blanchard, F. and C. Maneschy (2010), Amaz'hommes, sciences de l'homme et sciences de la nature en Amazonie, chapter vers 'un développement durable des pêcheries 
traditionnelles côtiéres amazoniennes: intégrer les sciences humaines aux sciences naturelles et économique' Guyane: lbis Rouge Editions, pp. 371-382.

Chaboud, C., P. Vendeville, F. Blanchard, and A. Viera (2008), 'Bio-economic modelling as an integrative tool assess the dynamics of fisheries facing global economic environmental changes : the example of the French Guyana shrimp fishery', in Coping with Global Change in Marine Social-ecological Systems: Programme and Abstracts, Rome: FAO, p. 23.

Chapel, L., G. Deffuant, S. Martin, and C. Mullon (2008), 'Defining yield policies in a viability approach', Ecological Modelling 212: 10-15.

Cury, P.A. and V. Christensen (2005), 'Quantitative ecosystem indicators for fisheries management', ICES Journal of Marine Science 62: 307-310.

Cury, P., C. Mullon, S. Garcia, and L.J. Shannon (2005), 'Viability theory for an ecosystem approach to fisheries', ICES Journal of Marine Science 62: 577-584.

De Lara, M. and L. Doyen (2008), Sustainable Management of Natural Resources: Mathematical Models and Methods, Berlin: Springer Verlag.

Doyen, L. and M. De Lara (2010), 'Stochastic viability and dynamic programming', Systems and Control Letters 59: 629-634.

Doyen, L., M. De Lara, J. Ferraris, and D. Pelletier (2007), 'Sustainability of exploited marine ecosystems through protected areas: a viability model and a coral reef case study', Ecological Modelling 208: 353-366.

Doyen, L., O. Thébaud, C. Béné, et al. (2012), 'A stochastic viability approach to ecosystem-based fisheries management', Ecological Economics 75: 32-42.

FAO (2003), Fisheries Management. 2: The Ecosystem Approach to Fisheries, FAO Technical Guidelines for Responsible Fisheries No. 4 (Suppl 2), Rome: FAO.

FAO (2010), The State of World Fisheries and Aquaculture, Rome: FAO Fisheries and Aquaculture Department.

Garcia, S. and J.R. Grainger (2005), 'Gloom and doom? The future of marine capture fisheries', Philosophical Transactions of the Royal Society B - Biological Sciences 360: 21-46.

Garcia, S., E.H. Allison, N. Andrew, et al. (2008), Towards Integrated Assessment and Advice in Small-Scale Fisheries: Principles and Processes, FAO Fisheries and Aquaculture Technical Paper No. 515, Rome: FAO.

Grafton, R.Q., T. Kompas, and R.W. Hilborn (2007), 'Economics of overexploitation revisited', Science 318: 1601-1601.

Hall, S. J. and B. Mainprize (2004), 'Towards ecosystem-based fisheries management', Fish and Fisheries 5: 1-20.

Hilborn, R. (2007), 'Defining success in fisheries and conflicts in objectives', Marine Policy 31: 153-158.

Holling, C.S. (1959), 'Some characteristics of simple types of predation and parasitism', Canadian Entomologist 91: 385-398.

INSEE (2011), 'Projections de population l'horizon 2040, Plus d'un demi-million de Guyanais', Technical report, Cayenne: INSEE.

Jennings, S. (2005), 'Indicators to support an ecosystem approach to fisheries', Fish and Fisheries 6: 212-232.

Leopold, M. (2004), Guide des Poissons de Mer de Guyane, Plouzane: Ifremer.

Link, J.S. (2005), 'Translating ecosystem indicators into decision criteria', ICES Journal of Marine Science 62: 569-576.

Magurran, A.E. (2007), 'Species abundance distributions over time', Ecology Letters 10: 347-354.

Marasco, R.J., D. Goodman, C.B. Grimes, P.W. Lawson, A.E. Punt, and T.J. Quinn (2007), 'Ecosystem-based fisheries management: some practical suggestions', Canadian Journal of Fisheries and Aquatic Sciences 64: 928-939. 
Mardle, S. and S. Pascoe (2000), 'Use of evolutionary methods for bioeconomic optimization models: an application to fisheries', Agricultural Systems 66: 33-49.

Martinet, V. and L. Doyen (2007), 'Sustainability of an economy with an exhaustible resource: a viable control approach', Resource and Energy Economics 29: 17-39.

Mullon, P., C. Cury, and L. Shannon (2004), 'Viability model of trophic interactions in marine ecosystems', Natural Resource Modeling 17: 71-102.

Pauly, D. and R. Watson (2005), 'Background and interpretation of the "Marine Trophic Index" as a measure of biodiversity', Philosophical Transactions of the Royal Society B - Biological Sciences 360: 415-423.

Péreau, J.-C., L. Doyen, L. Little, and O. Thébaud (2012), 'The triple bottom line: meeting ecological, economic and social goals with individual transferable quotas', Journal of Environmental Economics and Management 63: 419-434.

Pitcher, T.J. (2001), 'Fisheries managed to rebuild ecosystems? Reconstructing the past to salvage the future', Ecological Applications 11: 601-617.

Plaganyi, E. (2007), Models for an Ecosystem Approach to Fisheries, Fisheries Technical Paper No. 477, Rome: FAO.

Rice, J.C. (2000), 'Evaluating fishery impacts using metrics of community structure', ICES Journal of Marine Science 57: 682-688.

Sathianandan, T.V. and J. Jayasankar (2009), 'Managing marine fishery in Kerala through simulation using surplus production model, genetic algorithm and spectral methods', Indian Journal of Fisheries 56: 163-168.

Thébaud, O. and F. Blanchard (2011), Fishing the Food Web: Integrated Analysis of Changes and Drivers of Change in Fisheries of the Bay of Biscay, Hoboken, NJ: Wiley-Blackwell, pp. 90-104.

Worm, B., E.B. Barbier, N. Beaumont, et al. (2006), 'Impacts of biodiversity loss on ocean ecosystem services', Science 314: 787-790. 